\title{
Postoperative Pain Profile After Major Cervicofacial Cancer Surgery
}

\author{
Fanny Garnier, Cyrus Motamed, Philippe Sitbon, and Jean-Louis Bourgain
}

\section{ABSTRACT}

Background: Despite its anticipation, postoperative pain may be still poorly managed in some cases, such as in patients undergoing major cervicofacial cancer surgery. Indeed, the postoperative pain associated with these surgeries is complex and multifactorial.

Objective: To assess the profile of postoperative pain scores and opioid requirements in a cohort of consecutive patients undergoing major cancer cervicofacial surgery with or without reconstruction.

Methods: A cohort of 42 consecutive patients was studied. The following parameters were recorded: patients characteristics, type of surgery, preoperative medication preoperative pain scores, and postoperative pain score (5-point numerical verbal scale) upon arrival at the postanesthesia care unit (PACU) and at Day 1 to Day 7 (11-point visual numeric scale), the presence or absence of neuropathic and/or chronic pain one year later (determined by a phone interview), and morphine consumption.

Results: All patients had a pain score of less than 3 in the PACU. From postoperative day 1 to day 7 , pain scores were extremely variable and stayed high or even increased up to 7 in many patients. At the one-year phone interview, some patients had neuropathic and chronic pain.

Discussion: Postoperative pain profiles in major cervicofacial cancer are complex, with high interindividual variability and with cases with neuropathic patterns and high pain scores that can last up to 7 days postoperatively.

Keywords: postoperative pain, cancer surgery, head and neck, cervicofacial, chronic pain
Published Online: March 8, 2021

ISSN: $2736-5476$

DoI : 10.24018/ejclinicmed.2021.2.2.20

Fanny Garnier

University of Paris Sud 11, Departement of anesthesia Gustave Roussy cancer Campus, Villejuif 94080 Cedex, France

(e-mail: fanny-bvs@hotmail.com)

Cyrus Motamed *

University of Paris Sud 11, Departement of anesthesia Gustave Roussy cancer Campus, Villejuif 94080 Cedex, France

(e-mail: cyrus.motamed@ ${ }^{@}$ gustaveroussy.fr)

\section{Philippe Sitbon}

University of Paris Sud 11, Departement of anesthesia Gustave Roussy cancer Campus, Villejuif 94080 Cedex, France

(e-mail: philippe.sitbon ${ }^{\circledR}$ gustaveroussy.fr)

\section{Jean-Louis Bourgain}

University of Paris Sud 11, Departement of anesthesia Gustave Roussy cancer Campus, Villejuif 94080 Cedex, France (e-mail: bourgainj1@ orange.fr)

*Corresponding Author

\section{INTRODUCTION}

Despite progress in its management and its anticipation, postoperative pain still remains underestimated or poorly managed in some patients, including cancer patients who have undergone major cervicofacial surgery cancer [1-3]. Indeed, pain is frequently present at the time of cancer diagnosis in 20 to $48 \%$ of these patients [4, 5], and it tends to worsen even without surgery. Traditionally, postoperative pain scores are initially high but usually decrease within 72 h. However, patients who undergo major cervicofacial surgery can show unpredictable individual peaks of postoperative pain, and wide interindividual variability is reported. Patients with moderate and or severe pain preoperatively often report significantly greater pain scores and consume greater amounts of opioids [6].

Anticipating the onset or worsening of pain is an essential component of postoperative pain management. Inadequate postoperative pain control is, at a minimum, a source of discomfort, while in the long term it can lead to chronic or persistent pain [6] and indirectly to a decrease in the patient's quality of life [7]. Consequently, effective anticipation of postoperative pain and its control is associated with a lower morbidity and shorter length of hospital stay [8].

Several specific surgical site-related factors are responsible for generating postoperative pain after cervicofacial surgery and reconstruction. The most important of these factors are cancer infiltration, mucosal ulceration, and the presence of rich innervation [9]. Pain is often triggered by coughing or swallowing reflexes. Damage to the accessory nerve or sympathetic innervation can also be responsible for specific pain syndromes. Signs of central sensitization (allodynia and hyperalgesia) are also reported. In this context, the onset of pain may be delayed compared to the surgery date [10].

These complex mechanisms and variants can impair the effectiveness of conventional analgesic treatments, including morphine patient controlled analgesia (PCA). Unacceptable pain, even at rest, might be present in up to half of the patients who undergo cervicofacial cancer surgery [6]. The French guidelines recommend the prevention of postoperative pain by sparing nerves and muscles during surgery and by treatment using morphine PCA [11]. However, the level of evidence for the success of these approaches is weak because the literature contains very few randomized prospective studies and because the nature and profile of the pain is poorly 


\section{described.}

The primary objective of the present study was to evaluate the intensity, evolution, and type of pain after complex cervicofacial cancer surgery. A secondary objective was to assess the possible relationship between immediate postoperative pain and subsequent chronic pain. The information provided by this study is an important first step toward optimizing overall pain management in this high-risk patient population.

\section{METHODS}

This observational prospective study was conducted in a major cancer hospital from January to March 2015. A letter of information was given to patients, and oral consent was obtained for each patient. The Institutional Review Board of our hospital approved publication of the study findings. Inclusion criteria were all patients scheduled for major cervicofacial cancer surgery (major surgery was identified as tumor removal with or without flap reconstruction) who require post-operative surgical ICU monitoring and/or who had a surgery duration $>4 \mathrm{~h}$. Exclusion criteria were thyroidectomy for thyroid cancer, patients younger than 18 years, pre-operative cognitive dysfunction, non-French speaking patients, predicted short length of stay ( $<7$ days), or patients with life-threatening complications (e.g., a need for mechanical ventilation with sedation) (Figure 1).

Anesthesia management was standardized for all patients as propofol and remifentanil for induction. Desflurane and remifentanil using target controlled infusion were both titrated based on hemodynamic parameters, the bi-spectral index, and a ketamine infusion (bolus $0.3 \mathrm{mg} / \mathrm{kg}$, then 0.15 $\mathrm{mg} / \mathrm{kg} / \mathrm{h}$ ). Dexamethasone (8 $\mathrm{mg} \mathrm{IV}$ ) and ondansetron (4 mg) were used for prevention of postoperative nausea and vomiting. A multimodal post-operative pain treatment, based on the guidelines of the French Society of Anesthesia and Intensive Care (SFAR) and the French Society of Head and Neck Surgery and Otorhinolaryngology (SFORL), was anticipated with acetaminophen (1g), tramadol (100 mg), nefopam $(20 \mathrm{mg})$, and morphine $(0.10 \mathrm{mg} . \mathrm{kg}-1)$ one hour before the end of surgery. Use of nonsteroidal antiinflammatory drugs (NSAIDs; ketoprofen) was at the discretion of the anesthesiologist in charge, in coordination with the surgical teams. Post-operative pain medications (acetaminophen, tramadol, and nefopam) were continued throughout the study. A PCA pump was programmed to deliver a $1 \mathrm{mg}$ bolus with a lockout interval of $10 \mathrm{~min}$ without background infusion for $48 \mathrm{~h}$ postoperatively. The analgesics were then continued by the enteral route, based on acetaminophen, codeine, and oral morphine, depending on postoperative pain score assessment.

In cases of reconstructive surgery using a fibular free flap, a catheter was inserted tightly to the fibular nerve by the surgeons to infuse ropivacaine $(2 \%)$ at $5 \mathrm{ml} / \mathrm{h}$ for the first 48 h. In the post-anesthesia care unit (PACU), the pain scores were assessed using a 5-point numeric verbal scale (NVS) from 0 to 4 , where $0=$ no pain, $1=$ mild pain, $2=$ moderate pain, 3 = intense pain, and $4=$ maximum pain.

In case of anesthesia longer than $12 \mathrm{~h}$, patients were transferred directly to the surgical intensive care unit (SICU). These patients received the same analgesic treatment, but the initial assessment of pain was not available in the anesthetic chart and was transcribed from the SICU chart.

From postoperative day 1 (POD1) through POD7, pain scores were evaluated twice by nurses using an 11-point visual numeric scale (VNS) (where $0=$ no pain and $10=$ maximum tolerable pain). In addition, the POD1and POD7 assessments of pain were detailed using several criteria, including maximal pain in the tumor zone, flap removal zone, and neuropathic pain, as described with DN4 criteria $[12,13]$ (Table 1); motor deficit and pain related to accessory nerves (neuralgia); and wish or need for other analgesics. The opioid side effects and the patient level of satisfaction were evaluated on a daily basis on a scale from 0 to 10 . Surgical techniques, intraoperative anesthesia, and analgesic consumption were extracted from the computerized medical reports. Pain level was assessed daily by nurses using the same VNS scale. As several values were noticed on the nurse reports, average values were calculated each day from POD1 to POD7. One year after surgery, the patients were reached by phone interview to describe and define their current pain, if any.

Statistical analyses were carried out using Xlstat ${ }^{\circledR}$ with the $\chi 2$ test and the Kolmogorov-Smirnov test for non-parametric variables. To enhance the power of our study, we also extracted the pain scores upon arrival in the PACU for 200 additional patients undergoing the same type of surgery in the same period (up to 6 months). Comparison of those scores with the pain scores of the present study group allowed us to confirm that the initial pain scores reflected the scores of the majority of these types of patients.

\section{RESULTS}

Forty-two patients (male/female: 32/12; American Society of Anesthesiology (ASA) II 85\%; III 15\%) were included between January 2015 and March 2015 (Figure 1). The demographic characteristics, preoperative pain scores, initial tumor sites and previous treatments, types of surgery and/or reconstruction are presented in Table 1 . The types of surgery were primary tumor resection for 25 patients, recurrence resection for 11 patients, surgical complications for 5 patients, and osteoradionecrosis for 1 patient (Table 2).

Pain scores upon arrival at and discharge from the PACU were always less than 3 (Table 3). These values were confirmed after extraction of data from 277 additional patients for the following six-month period (Table 4). Despite the accessibility to morphine PCA, the pain scores increased during the first $24 \mathrm{~h}$ (Table 5). New analgesic treatments were therefore prescribed for five patients (four were treated with NSAIDs and one with Ketamine), and eleven patients had additional administration of analgesics.

The VNS scores remained high during the first week. The individual variability of the pain scores throughout the study was an important feature (Table 5). Morphine PCA consumption was also extremely variable between the patients (Figure 2); 18 patients required less than $10 \mathrm{mg}$ during the first $24 \mathrm{~h}$ after surgery, while 1 patient required more than $100 \mathrm{mg}$. The pain scores slightly decreased during the first week in the cervicofacial area (tumor site excision) but not in the flap removal site (Figure 3).

Pain was identified as neuropathic at postoperative POD1 in six patients and at POD7 in five patients, and overall corresponding to ten different patients. Neuropathic pain was 
not relieved by the treatment, and the proportion of painful patients was higher among those who had neuropathic pain at POD 7 (36\% vs.10\%; p=0.045). Accessory nerve neuralgia was reported by five patients at POD1 and six at POD7, with a high pain score level (average VNS 4.7 at POD1; 3.7 at POD7), even if surgery did not require a section of the accessory nerve.

Patient satisfaction with postoperative analgesic management was high (8.7/10), including the sub-population of patients receiving preoperative analgesics (8.9/10). However, at POD1, 16 patients needed additional analgesic medications and 11 at required it at POD7. Patients who had a pain score $>40$ on the seventh day tended to be women ( $80 \%$ female vs. $40 \%$ men; $p=0.045$ ) and had neuropathic pain, a lower level of satisfaction, a higher demand for analgesic medications, and bone-related pain (66 vs. 35\%; $\mathrm{p}<0.05)$. However, recurrent surgery $(\mathrm{n}=2[25 \%]$ vs. $\mathrm{n}=13$ [38]) did not achieve significance.

\section{A. Long term (one-year) assessment}

One year after surgery, fifteen patients $(32 \%)$ responded by phone, five had died, and the others could not be contacted. Nine patients reported chronic pain, with neuropathic characteristics in four patients. The pain was localized at the flap harvest site (two patients) and the accessory nerve (one patient). An early relapse was responsible for the reemergence of pain in two patients.

\section{DISCUSSION}

This study shows that, despite the anticipation of postoperative pain and the success of postoperative pain management upon arrival in the PACU, postoperative pain control during the first postoperative week was suboptimal in our patients. In the PACU, the pain scores were mostly low and clinically acceptable upon arrival; however, the scores increased at POD1 and remained high during the first week. More than half the patients had VNS scores above or equal to 3 and sometimes up to 7 on POD7. Many patients (38\%) would have liked more effective analgesics for their pain management. Most importantly, high intra- and interindividual variability of pain scores was noted during the first week.

The available data are very sparse for the profile of postoperative pain after cervicofacial cancer complex surgery, and the results of this study may contribute to a better pain management in these difficult situations. The variability of postoperative pain after cervicofacial surgery has previously been described for up to day 5 [4]. This study extended the profile to up to 7 days and found similar findings, with no major trend in the decrease in pain scores, as observed in other surgical situations [14]. The number of patients included in this study was insufficient to assess the risk factors for high postoperative pain; nevertheless, they were probably highly representative of our practice, as we checked an extra 277 patients having the same type of surgery in the following 6-month period. Those patients had similar pain scores upon arrival in the PACU. However, patients having surgery with mandibular osteosynthesis showed higher pain levels and pain with a neuropathic component during the first week.

Postoperative pain might also become a long-term problem in some patients by persisting for one year after surgery, with or without neuropathic characteristics. Here, again, the limited number of patients who responded to the late telephone interview did not allow us to draw general conclusions. The pain scores were measured by the VNS during the assessment at POD1 through POD7: These values were not necessarily the average scores of pain throughout the day.

Pain assessment by nurses was not homogeneous (Figure 3 ), as it did not take into account either the dynamic or rest situations or conditions such as swallowing, coughing, mobilization, or other painful stimulations. In addition, the pain site was seldom recorded. Therefore, these measures were difficult to interpret, even if the scores were comparable to those measured at POD1 and POD7 using a standardized questionnaire. We used the optimal measurement scale for pain in this context since the VNS is reproducible, easy to use, and may be adopted by the patients themselves from the very first postoperative hours. A previous retrospective study quantified the effectiveness of pain management in head and neck cancer patients [10] and showed high postoperative pain scores up to day 5 , but the type of surgery and the pain category were not specifically defined. Nevertheless, the conclusions of that study are in accordance with our findings.

The VNS and Visual Analog Scale (VAS) are comparable in sensitivity $[15,16]$. The VNS is a fast and easy way to estimate the pain intensity, and it allows quantitative evaluation to classify patients in relation to each other. It is also preferred by patients for its simplicity of use [15] and by researchers for its visual or verbal collection. However, these are one-dimensional scales, and they provide no information on the origins, characteristics, and impacts of pain. We chose to use these simple scales over more complex questionnaires (e.g., the Wisconsin Brief Pain Inventory) given the early postoperative context and the presence of a tracheostomy cannula that impeded oral expression in more than half of our patients.

By contrast, the VAS and, by extension, the VNS have high reproducibility in the same patient [17], which reinforces its use but only to evaluate the pain in real time and not retrospectively [18].

However, the use of the VNS as a numerical value is questioned by some authors [19], as the pain scores may not follow a normal distribution, Nevertheless, the changes in VNS scores are linear and correlate positively with painful sensations [20]. Therefore, the use of the VNS to evaluate the effectiveness of analgesic therapies is justified in this context.

Neuropathic pain characteristics were found in six patients on POD1 and in five patients on POD7, involving ten different subjects; therefore, we assumed that neuropathic pain may be present in the immediate postoperative period and it may appear, disappear, or persist during the first week. It affects a significant proportion of patients (24\%), and it may be difficult to treat. This finding raises several questions for effective therapeutic action for uncontrolled neuropathic pain. Currently, no fast and efficient analgesic is available for neuropathic pain; therefore, a background treatment should be introduced as early as possible in the preoperative period in order to avoid possible postoperative morphine overdoses. We acknowledge that the number of patients studied is not sufficient to identify risk factors for neuropathic pain. Finally, the proportion of acute neuropathic pain that really evolves into chronic pain remains to be determined.

One previous study focused on a very precise population in the literature: patients with frequent alcohol-tobacco intoxication [21]. In these patients, an underlying depressive 
mood is sometimes related to the pain itself and can alter the assessment of pain and make it more difficult to quantify it [22]. Our population was heterogeneous: the subjects studied were at different stages of the disease, with $38 \%$ of the interventions performed in patients who had already undergone cervicofacial cancer surgery, $14 \%$ who had a reconstructive surgery with sequelae of major cancers, and $28 \%$ with a history of cervicofacial radiotherapy. The inflammatory status may be modified by the preoperative history, such as local inflammation, infection, and radiotherapy, or by postoperative complications. All these factors may have influenced the inflammatory component of the pain. Inter-individual variability is also a known factor in the study of pain and especially in post-operative pain [16]. This important variability from one patient to another is found in clinical practice: it is one of the main obstacles to the implementation of protocols for systematic preventive analgesia and makes the use of self-assessment tools necessary for pain assessment.

The pathway behind the disparity observed between patients for postoperative pain is not yet known. These factors may include preoperative or surgical risk factors that are still unidentified, but other physiological mechanisms may also be involved. A relationship may exist between pain and preoperative anxiety or between postoperative inflammation and activation of the sympathetic autonomic nervous system (e.g., like first bite syndrome). First bite syndrome is a potential complication of infratemporal fossa surgery, or surgery of the deep lobe of the parotid gland and the parapharyngeal space. It is described as an acute and intense pain in the parotid region occurring during the first bite of each meal and is related to damage to the sympathetic innervation of the parotid gland [23]. The incidence of postoperative neck pain is higher when the cervical plexus is sacrificed $(72 \%)$ rather than preserved $(37 \%)$ [24]. These different hypotheses are being explored by other teams but are difficult to highlight given the multiplicity of confounding factors [2]. In addition, we did not assess free flaps' or other postoperative infections that occur later in the hospitalization [25] and in case of new surgical interventions that might generate new or higher postoperative pain. Indeed, our very small number of patients assessed after 1 year $(n=15)$ does not permit us to draw specific conclusions.

All patients received continuous infusions of ketamine during surgery. Prevention of postoperative pain upon arrival in PACU was acceptable, but it seems to be insufficient and it would be interesting to test other strategies, like the continuous administration of intravenous lidocaine. However, our results encourage the development of additional analgesic techniques that could be evaluated secondarily. One could measure the contribution of NSAIDs on the inflammatory component of the pain in the perioperative and immediate postoperative periods. Single shot regional analgesia or continuous infusions through a catheter also need to be developed, especially on the upper limb. One point that should be emphasized since this study was performed is that some protocol changes have occurred in postoperative pain management, including the use of intraoperative free opioid analgesia, as well as additional regional techniques. These changes need to be assessed in future studies.

In conclusion, major head and neck cancer surgery is painful even after $48 \mathrm{~h}$, and postoperative pain may continue up to the first week after the surgery. Targeting only the immediate arrival in PACU appears not to be sufficient. The polymorphism of the painful symptoms involves diverse mechanisms: inflammation, stimulation of the cervical sympathetic nerves, and neuropathic pain. This fully justifies future randomized studies in specific surgeries that anticipate postoperative pain for a longer period than $48 \mathrm{~h}$ by the administration of other analgesics, such as anti-inflammatory medication or other techniques such as regional anesthesia and psychological approaches.

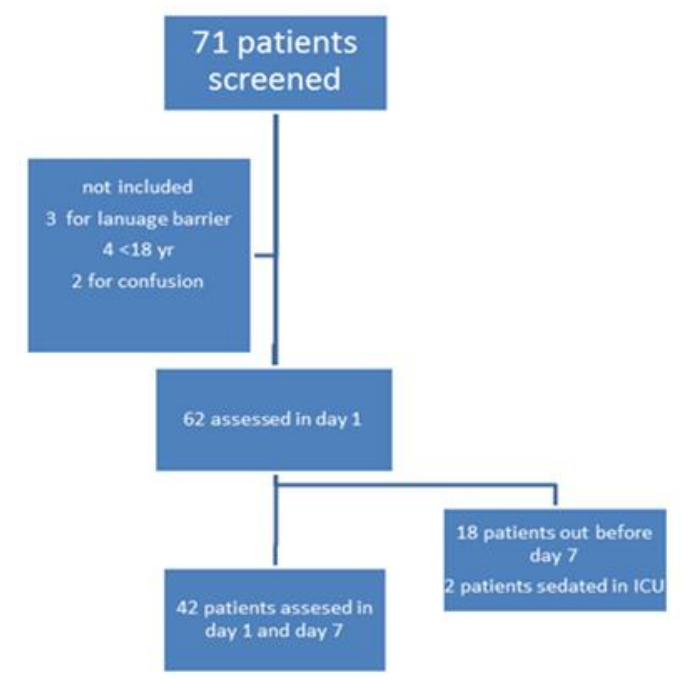

Fig. 1. Flowchart for patient selection

\begin{tabular}{|c|c|c|}
\hline Age (years) & Mean [range] & $62.6[46-75]$ \\
\hline Sex ratio $(\mathrm{M} / \mathrm{F}) \%$ & & $(32 / 10) 76 / 24$ \\
\hline \multirow{3}{*}{ Comorbidities } & Alcohol abuse n (\%) & $8(20)$ \\
\hline & Tobacco n $(\%)$ & $7(17)$ \\
\hline & Diabetes & $8(20)$ \\
\hline \multirow{3}{*}{$\begin{array}{l}\text { Body mass index } \\
\left(\mathrm{kg} / \mathrm{m}^{2}\right)(\%)\end{array}$} & Underweight $(<18)$ & $4(10)$ \\
\hline & Overweight (25-29.9) & $15(35)$ \\
\hline & Obesity $(>30)$ & $9(21)$ \\
\hline \multirow{3}{*}{$\begin{array}{l}\text { ASA } \\
\mathrm{n}(\%)\end{array}$} & Class 1 & $2(5)$ \\
\hline & Class 2 & $34(83)$ \\
\hline & Class 3 & $6(14)$ \\
\hline \multirow{4}{*}{$\begin{array}{c}\text { Preoperative } \\
\text { treatment } \\
\mathrm{n}(\%)\end{array}$} & Antidepressants & $5(11)$ \\
\hline & Anxiolytics & $7(17)$ \\
\hline & Non-opioid analgesics & $17(40)$ \\
\hline & Opioid analgesics & $7(17)$ \\
\hline \multirow{2}{*}{$\begin{array}{c}\text { Drinking status } \\
\mathrm{n}(\%)\end{array}$} & Alcohol cessation & $6(14)$ \\
\hline & Refusal of weaning & $2(5)$ \\
\hline \multirow{3}{*}{$\begin{array}{c}\text { Preoperative cancer } \\
\text { treatment } \\
n(\%)\end{array}$} & Radiotherapy & $12(28)$ \\
\hline & $\begin{array}{l}\text { Chemotherapy }<1 \\
\text { month }\end{array}$ & $1(2)$ \\
\hline & Cervicofacial surgery & $16(37)$ \\
\hline \multirow{4}{*}{$\begin{array}{c}\text { Preoperative pain } \\
\text { score [0 to } 10] \\
\text { n }(\%)\end{array}$} & $=0$ & $24(57)$ \\
\hline & $>0$ and $<3$ & $13(30)$ \\
\hline & $>3$ and $<6$ & $4(10)$ \\
\hline & $>6$ & $1(2)$ \\
\hline
\end{tabular}


TABLE II: SURCIGAL CHARACTERISTICS

\begin{tabular}{|c|c|c|}
\hline \multirow{4}{*}{$\begin{array}{l}\text { Indication for } \\
\text { surgery } \\
\mathrm{n}(\%)\end{array}$} & First line treatment & $25(60)$ \\
\hline & Cancer recurrence & $11(26)$ \\
\hline & Reconstructive surgery & $5(2)$ \\
\hline & Osteoradionecrosis & $1(2)$ \\
\hline \multirow{7}{*}{$\begin{array}{c}\text { Tumor localization } \\
\mathrm{n}(\%)\end{array}$} & Larynx & $10(4)$ \\
\hline & Hypopharynx & $3(7)$ \\
\hline & Tongue & $17(40)$ \\
\hline & Oropharynx & $4(10)$ \\
\hline & Salivary glands & $3(7)$ \\
\hline & Nasopharynx & $1(2)$ \\
\hline & Face & $4(9)$ \\
\hline \multirow{7}{*}{$\begin{array}{l}\text { Flap } \\
\mathrm{n}(\%)\end{array}$} & Fibula & $8(20)$ \\
\hline & Forearm & $7(16)$ \\
\hline & Latissimus dorsi & $7(16)$ \\
\hline & Lateral thigh perforator & $6(14)$ \\
\hline & $\begin{array}{l}\text { Pectoralis major } \\
\text { musculocutaneous }\end{array}$ & $3(7)$ \\
\hline & Cutaneous flap & $2(4)$ \\
\hline & No flap & $9(21)$ \\
\hline \multirow{3}{*}{$\begin{array}{c}\text { Postoperative nerve } \\
\text { block } \\
\mathrm{n}(\%)\end{array}$} & Intercostal & $5(12)$ \\
\hline & Thigh & $3(7)$ \\
\hline & Fibular & $8(20)$ \\
\hline \multirow{3}{*}{ Intraoperative data } & $\begin{array}{l}\text { Duration of surgery (min) } \\
\text { (mean [range]) }\end{array}$ & $468[150-687]$ \\
\hline & Tracheotomy n (\%) & $33(78 \%)$ \\
\hline & $\begin{array}{l}\text { Remifentanil dose } \\
(\mu \mathrm{g} / \mathrm{kg} / \mathrm{min} ; \text { mean [range] })\end{array}$ & $3.9[1.9-7.4]$ \\
\hline \multirow{3}{*}{$\begin{array}{l}\text { Intraoperative } \\
\text { medication } \\
\mathrm{n}(\%)\end{array}$} & $\begin{array}{l}\text { Non steroid anti- } \\
\text { inflammatory }\end{array}$ & $5(12 \%)$ \\
\hline & Dexamethasone $8 \mathrm{mg}$ & $38(91 \%)$ \\
\hline & Ondansetron $4 \mathrm{mg}$ & $36(85 \%)$ \\
\hline
\end{tabular}

TABLE III: NUMERICAL VERBAL SCALE UPON ARRIVAL AND BEFORE LEAVING THE PACU

\begin{tabular}{|c|c|c|c|c|}
\hline $\begin{array}{c}\text { Pain } \\
\text { scores }\end{array}$ & \multicolumn{2}{|c|}{ Study patients $(\mathrm{n}=42)$} & \multicolumn{2}{c|}{6 month period (n=277) } \\
\hline PACU & $\begin{array}{c}\text { upon arrival } \\
\text { discharge }\end{array}$ & $\begin{array}{c}\text { upon } \\
\text { arrival } \\
\text { PACU }\end{array}$ & $\begin{array}{c}\text { before } \\
\text { discharge }\end{array}$ \\
\hline $0(\%)$ & 54.1 & 57.1 & 61.7 & 65.5 \\
\hline $1(\%)$ & 19.3 & 22.4 & 15.2 & 26.7 \\
\hline $2(\%)$ & 14.2 & 20.5 & 12.3 & 5.9 \\
\hline $3(\%)$ & 12.4 & 0 & 6.1 & 0.8 \\
\hline $4(\%)$ & 0 & 0 & 0.7 & 1 \\
\hline missing & 0 & 0 & 4 & 0 \\
\hline data & & 0 & & \\
\hline
\end{tabular}

Numerical Verbal Pain scores in the PACU $(0=$ no pain at all, $1=$ mild pain, $2=$ moderate pain, $3=$ intense pain, $4=$ maximum pain)
TABLE IV: CHARACTERISTICS OF PAIN AT POD1 AND POD7

\begin{tabular}{|c|c|c|c|}
\hline & & POD1 & POD7 \\
\hline \multirow{3}{*}{ VNS } & $\begin{array}{l}\text { Cervicofacial site } \\
(\text { mean }[\mathrm{CI}])\end{array}$ & $3.5[0-7.9]$ & $2.5[0-6.9]$ \\
\hline & Flap & 3 [0-6.9] & $2.8[0-7.0]$ \\
\hline & Shoulder pain & 4.7 & 3.7 \\
\hline \multirow{4}{*}{ Type of pain } & Nociceptive & $36(86 \%)$ & $34(81 \%)$ \\
\hline & Neuropathic & 0 & $2(5 \%)$ \\
\hline & $\begin{array}{l}\text { Nociceptive and } \\
\text { neuropathic }\end{array}$ & $6(14 \%)$ & $3(7 \%)$ \\
\hline & Other & & $3(7 \%)$ \\
\hline $\begin{array}{l}\text { Acute and intense } \\
\text { pain }\end{array}$ & & $6(14 \%)$ & $3(7 \%)$ \\
\hline $\begin{array}{l}\text { Additional } \\
\text { analgesic } \\
\text { treatment }\end{array}$ & & $5(12 \%)$ & 0 \\
\hline $\begin{array}{l}\text { Request for } \\
\text { further analgesic } \\
\text { treatment }\end{array}$ & & $11(26 \%)$ & $11(26 \%)$ \\
\hline
\end{tabular}

$\mathrm{POD}=$ postoperative day

$\mathrm{VNS}=$ visual numeric scale

TABLE V: CLASSIFICATION OF PATIENTS FROM POD1 TO POD7 INTO 2 GROUPS FOR THOSE HAVING MEDIAN VNS LESS THAN OR MORE THAN 7/10, AT POD1: VALUES ARE MEDIAN (INTERQUARTILE RANGE) MINIMUM-MAXIMUM

\begin{tabular}{|c|c|c|}
\hline & VNS $<7 \quad n=34$ & $\mathrm{VNS}>7 \quad \mathrm{n}=8$ \\
\hline $\begin{array}{l}\text { POD1 } \\
\text { median(interquartile) } \\
\text { min-max }\end{array}$ & $\begin{array}{c}3(2-4) \\
0-6\end{array}$ & $\begin{array}{c}8(7-9) \\
7-10\end{array}$ \\
\hline $\begin{array}{l}\text { POD2 } \\
\text { median(interquartile) } \\
\text { min-max }\end{array}$ & $\begin{array}{c}3(2-4) \\
0-8\end{array}$ & $\begin{array}{c}5(5) \\
4-8\end{array}$ \\
\hline $\begin{array}{l}\text { POD3 } \\
\text { median(interquartile) } \\
\text { min-max }\end{array}$ & $\begin{array}{c}3(0-5) \\
0-7\end{array}$ & $\begin{array}{c}5(5-6) \\
1-10\end{array}$ \\
\hline $\begin{array}{l}\text { POD4 } \\
\text { median(interquartile) } \\
\text { min-max }\end{array}$ & $\begin{array}{c}2(0-3) \\
0-10\end{array}$ & $\begin{array}{c}4.5(3-6) \\
1-10\end{array}$ \\
\hline $\begin{array}{l}\text { POD5 } \\
\text { median(interquartile) } \\
\text { min-max }\end{array}$ & $\begin{array}{c}3(0-4) \\
0-10\end{array}$ & $\begin{array}{c}5(4-6) \\
2-9\end{array}$ \\
\hline $\begin{array}{l}\text { POD6 } \\
\text { median(interquartile) } \\
\text { min-max }\end{array}$ & $\begin{array}{c}2(0-4) \\
0-9\end{array}$ & $\begin{array}{c}5(4-6) \\
2-7\end{array}$ \\
\hline $\begin{array}{l}\text { POD7 } \\
\text { median(interquartile) } \\
\text { min-max }\end{array}$ & $\begin{array}{c}3(0-4) \\
0-8\end{array}$ & $\begin{array}{c}4(2-5) \\
0-7\end{array}$ \\
\hline
\end{tabular}

POD = postoperative day 


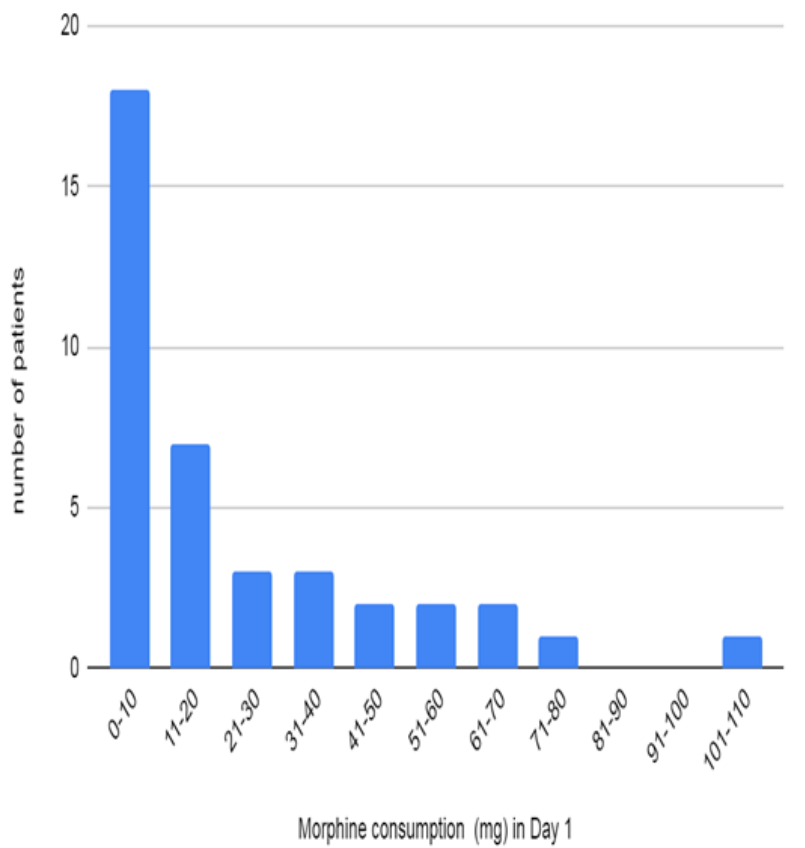

Fig. 2. Morphine consumption in the first 24 hours

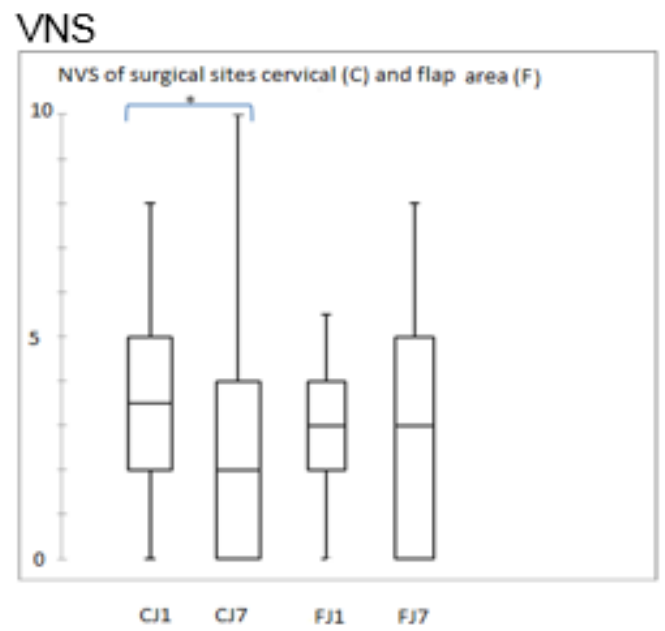

$\mathrm{p}<0.05$ in the cervical site comparison of D1 and D7 $\mathrm{POD}=$ postoperative day

Fig. 3. Visual numeric scale (VNS) scores during interviews at POD1 and POD7 for cervical site (C) and free flap harvest site (F)

\section{REFERENCES}

[1] Mom T, Commun F, Derbal C, Dubray C, Eschalier A, Bost P, et al. [Postoperative pain evaluation in the surgery of head and neck cancers]. Rev Laryngol Otol Rhinol (Bord). 1996;117(2):93-6.

[2] Sommer M, Geurts JW, Stessel B, Kessels AG, Peters ML, Patijn $\mathrm{J}$, et al. Prevalence and predictors of postoperative pain after ear, nose, and throat surgery. Arch Otolaryngol Head Neck Surg. 2009;135(2):124-30.

[3] Inhestern J, Schuerer J, Illge C, Thanos I, Meissner W, Volk GF, et al. Pain on the first postoperative day after head and neck cancer surgery. Eur Arch Otorhinolaryngol. 2015;272(11):34019.

[4] Chaplin JM, Morton RP. A prospective, longitudinal study of pain in head and neck cancer patients. Head Neck. 1999;21(6):531-7.

[5] Potter J, Higginson IJ, Scadding JW, Quigley C. Identifying neuropathic pain in patients with head and neck cancer: use of the Leeds Assessment of Neuropathic Symptoms and Signs Scale. J R Soc Med. 2003;96(8):379-83.

[6] Buchakjian MR, Davis AB, Sciegienka SJ, Pagedar NA, Sperry SM. Longitudinal Perioperative Pain Assessment in Head and
Neck Cancer Surgery. Ann Otol Rhinol Laryngol. 2017;126(9):646-53

[7] Lahtinen S, Koivunen P, Ala-Kokko T, Laurila P, Kaarela O, Liisanantti JH. Quality of life after free flap surgery for cancer of the head and neck in patients with or without postoperative complications. Eur Arch Otorhinolaryngol. 2018;275(10):257584.

[8] Turan A, Leung S, Bajracharya GR, Babazade R, Barnes T, Schacham YN, et al. Acute Postoperative Pain Is Associated With Myocardial Injury After Noncardiac Surgery. Anesth Analg. 2020;131(3):822-9.

[9] Bianchini C, Malago M, Crema L, Aimoni C, Matarazzo T, Bortolazzi S, et al. Post-operative pain management in head and neck cancer patients: predictive factors and efficacy of therapy. Acta Otorhinolaryngol Ital. 2016;36(2):91-6.

[10] Hinther A, Nakoneshny SC, Chandarana SP, Wayne Matthews T, Dort JC. Efficacy of postoperative pain management in head and neck cancer patients. J Otolaryngol Head Neck Surg. 2018;47(1):29.

[11] Espitalier F, Testelin S, Blanchard D, Binczak M, Bollet M Calmels $\mathrm{P}$, et al. Management of somatic pain induced by treatment of head and neck cancer: Postoperative pain. Guidelines of the French Oto-Rhino-Laryngology--Head and Neck Surgery Society (SFORL). Eur Ann Otorhinolaryngol Head Neck Dis. 2014;131(4):249-52.

[12] Bouhassira D, Attal N, Fermanian J, Alchaar H, Gautron M, Masquelier E, et al. Development and validation of the Neuropathic Pain Symptom Inventory. Pain. 2004;108(3):248 57.

[13] Mulvey MR, Boland EG, Bouhassira D, Freynhagen R, Hardy J, Hjermstad MJ, et al. Neuropathic pain in cancer: systematic review, performance of screening tools and analysis of symptom profiles. Br J Anaesth. 2017;119(4):765-74.

[14] Melson TI, Boyer DL, Minkowitz HS, Turan A, Chiang YK Evashenk MA, et al. Sufentanil sublingual tablet system vs. intravenous patient-controlled analgesia with morphine for postoperative pain control: a randomized, active-comparator trial. Pain Pract. 2014;14(8):679-88.

[15] Hawker GA, Mian S, Kendzerska T, French M. Measures of adult pain: Visual Analog Scale for Pain (VAS Pain), Numeric Rating Scale for Pain (NRS Pain), McGill Pain Questionnaire (MPQ), Short-Form McGill Pain Questionnaire (SF-MPQ), Chronic Pain Grade Scale (CPGS), Short Form-36 Bodily Pain Scale (SF-36 BPS), and Measure of Intermittent and Constant Osteoarthritis Pain (ICOAP). Arthritis Care Res (Hoboken). 2011;63 Suppl 11:S240-52.

[16] Hjermstad MJ, Fayers PM, Haugen DF, Caraceni A, Hanks GW Loge JH, et al. Studies comparing Numerical Rating Scales, Verbal Rating Scales, and Visual Analogue Scales for assessment of pain intensity in adults: a systematic literature review. J Pain Symptom Manage. 2011;41(6):1073-93.

[17] Goddard G, Karibe H, McNeill C. Reproducibility of visual analog scale (VAS) pain scores to mechanical pressure. Cranio. 2004;22(3):250-6.

[18] Liu WH, Aitkenhead AR. Comparison of contemporaneous and retrospective assessment of postoperative pain using the visual analogue scale. Br J Anaesth. 1991;67(6):768-71.

[19] Berger VW. Can pain be quantified numerically? J Rheumatol. 2006;33(11):2364-5; author reply 5 .

[20] Myles PS, Urquhart N. The linearity of the visual analogue scale in patients with severe acute pain. Anaesth Intensive Care 2005;33(1):54-8.

[21] Shaw R, Beasley N. Aetiology and risk factors for head and neck cancer: United Kingdom National Multidisciplinary Guidelines. J Laryngol Otol. 2016;130(S2):S9-S12.

[22] Bamonti PM, Moye J, Naik AD. Pain is associated with continuing depression in cancer survivors. Psychol Health Med. 2018;23(10):1182-95.

[23] Linkov G, Morris LG, Shah JP, Kraus DH. First bite syndrome: incidence, risk factors, treatment, and outcomes. Laryngoscope. 2012;122(8):1773-8

[24] Gane EM, McPhail SM, Hatton AL, Panizza BJ, O'Leary SP. Predictors of health-related quality of life in patients treated with neck dissection for head and neck cancer. Eur Arch Otorhinolaryngol. 2017;274(12):4183-93.

[25] Hojvig JH, Pedersen NJ, Charabi BW, Wessel I, Jensen LT, Nyberg $\mathrm{J}$, et al. Microvascular reconstruction in head and neck cancer - basis for the development of an enhanced recovery protocol. JPRAS Open. 2020;26:91-100. 